\title{
Why man's best friend, the dog, could also benefit from an anti-HER-2 vaccine (Review)
}

\author{
JUDIT FAZEKAS $^{1,2}$, IRENE FÜRDÖS ${ }^{1}$, JOSEF SINGER ${ }^{1,2}$ and ERIKA JENSEN-JAROLIM ${ }^{1,2}$ \\ ${ }^{1}$ Comparative Medicine, The Interuniversity Messerli Research Institute, University of Veterinary Medicine Vienna, \\ Medical University Vienna and University Vienna, Vienna $1210 ;{ }^{2}$ Institute of Pathophysiology and Allergy Research, \\ Center of Pathophysiology, Infectiology and Immunology, Medical University of Vienna, Vienna 1090, Austria
}

Received September 28, 2015; Accepted May 12, 2016

DOI: $10.3892 / \mathrm{ol} .2016 .5001$

\begin{abstract}
Human epidermal growth factor receptor-2 (HER-2) is a well-established target for anticancer precision medicine in humans. A HER-2 homologue with $92 \%$ amino acid identity has been described in canine mammary tumors, which is termed here as 'dog epidermal growth factor receptor-2 (DER-2)', with similar biological implications as those in human breast cancer. Both antigens can principally be immunologically targeted by anti-HER-2 antibodies, such as trastuzumab; however, the in vivo application of humanized antibodies to other species would lead to specific hypersensitivity reactions. Therefore, HER-2 mimotope vaccines that actively induce autologous trastuzumab-like immunoglobulins represent a novel and economic treatment option to overcome species-specific limitations. Thus, the present review proposes the implementation of clinical trials with HER-2 vaccines in canine cancer model patients with spontaneous DER-2 positive mammary gland carcinomas in order to assess their safety and efficacy. This approach would not only pave the way into the veterinary oncology market, but would also similarly generate robust data for human trials and facilitate the testing of novel combinatorial treatments.
\end{abstract}

Correspondence to: Professor Erika Jensen-Jarolim, Comparative Medicine, The Interuniversity Messerli Research Institute, University of Veterinary Medicine Vienna, Medical University Vienna and University Vienna, c/o 18-20 Währinger Gürtel, Vienna 1090, Austria

E-mail: erika.jensen-jarolim@meduniwien.ac.at

Abbreviations: AAV, adeno-associated virus; AAVLP, AAV-like particle; DER-2, dog epidermal growth factor receptor-2; EGFR, epidermal growth factor receptor; HER-2, human epidermal growth factor receptor-2

Key words: HER-2, dog, translational, cancer vaccine, oncology, mimotope

\section{Contents}

1. Introduction: Comparing HER-2 targeted therapies in human and canine cancer

2. HER-2 mimotope vaccines - a novel treatment approach

3. Canine mammary carcinomas resemble human disease

4. Translational relevance

5. Conclusion: Where we stand

\section{Introduction: Comparing HER-2 targeted therapies in human and canine cancer}

Human epidermal growth factor receptor-2 (HER-2) is overexpressed in $25-30 \%$ of human breast cancers due to gene amplification, thus defining 'HER-2-positive disease' (1-3). HER-2-overexpression in human breast cancer has been associated with increased metastatic potential (4), poor disease-free and overall survival, and poor responsiveness to chemotherapy in vitro and in vivo $(5,6)$. Besides surgery, radiation and the usual chemotherapy protocols, therapies used most successfully in HER-2-overexpressing cancers are those addressing HER-2 as a target on malignantly transformed cells $(7,8)$. These so called 'targeted therapies' are well established in human HER-2-positive breast cancer and several agents have been approved for this indication over the last years $(9,10)$. Examples of such targeted therapies that significantly improved disease outcome are trastuzumab (Herceptin ${ }^{\circledR}$; Hoffmann-La Roche AG, Basel, Switzerland) and pertuzumab (Perjeta ${ }^{\circledR}$; Hoffmann-La Roche AG) (11), two monoclonal antibodies used for passive immunotherapy in combination with different chemotherapy protocols (12), but tyrosine kinase inhibitors like lapatinib (Tyverb ${ }^{\circledR}$; GlaxoSmithKline plc., London, UK) have also been proven to be effective (13).

Hardly any of these targeted therapies have been adapted for the use in canine patients or have yet been studied in veterinary clinical trials. To date, only the tyrosine kinase inhibitors masitinib (Masivet ${ }^{\circledR}$; AB Science S.A., Paris, France) and toceranib (Palladia ${ }^{\circledR}$; Pfizer Inc., New York, NY, USA), each targeting c-Kit, have been successfully tested in clinical trials and have been approved for canine mast cell tumor patients $(14,15)$. In the case of toceranib, it was the efficacy of the human counterpart substance sunitinib (Sutent ${ }^{\circledR}$; Pfizer 
Inc.) that led to the independent development of a similar drug in $\operatorname{dog}_{s}(15,16)$.

A recent study revealed that in addition to a similar ErbB-2 overexpression rate in canine mammary gland tumors compared with the human disease counterpart (17-20), there was also an amino acid identity of $92 \%$ and a homology of 95\% between canine dog epidermal growth factor receptor-2 (DER-2) and human HER-2 (21). Moreover, it was demonstrated that the targeting of DER-2 with trastuzumab led to the growth inhibition of canine tumor cells (21), indicating a similar biology in canine mammary carcinomas as that of the HER-2 system in human patients (19). The DER-2 status of mammary tumors in dogs is not yet considered in veterinary medicine, although its expression could be important in terms of carcinogenesis and disease severity, as well as in the development of novel targeted drugs $(20,22)$.

\section{HER-2 mimotope vaccines - a novel treatment approach}

Trastuzumab, as aforementioned, is a humanized monoclonal antibody used for passive immunotherapy in human HER-2-positive breast cancer (12). In its humanized form, it is not applicable in comparative medicine studies, e.g., in canine models, as it represents a xenogeneic and highly immunogenic protein that is capable of inducing hypersensitivity (23-25). This risk can be minimized if the constant region domains are adapted to the given species $(24,26)$. Only two such chimeric canine antibodies have been reported to date. One is based on cetuximab (Erbitux ${ }^{\circledR}$; Merck KGaA, Darmstadt, Germany), a mouse-human chimeric anti-epidermal growth factor receptor (EGFR) antibody (26), and the second is a rituximab-like (MabThera ${ }^{\circledR}$; Hoffman-La Roche AG, Basel, Switzerland) antibody targeting the B-cell antigen cluster of differentiation (CD)20 (27). However, these approaches are cost intensive, which may limit their market value in comparative medical studies and veterinary oncology. The cost factor, as well as the induction of autologous antibodies would favor active immunotherapies such as a vaccine over passive immunotherapy, not only for translational or comparative studies, but also for human patients $(28,29)$.

A tumor vaccine acts as an active immunotherapy, training the immune system to induce polyclonal antibodies against a tumor-specific antigen. Several tumor vaccines are currently under clinical development in human breast cancer, aiming for the induction of antibodies against different tumor-associated proteins, e.g., mucin-1, telomerase reverse transcriptase or carcinoembryonic antigen (30). Correspondingly, several anti-HER-2 vaccines are also being studied in clinical trials, including NeuVax ${ }^{\mathrm{TM}}$, a CD8(+) T-cell-eliciting vaccine (31) and the AdHER2/neu dendritic cell vaccine, which is currently being tested in a phase I study (32).

Mimotopes, i.e. peptides mimicking protein, carbohydrate or lipid epitopes represent another novel and feasible option for cancer vaccines $(33,34)$. In previous studies, we developed a series of mimotope vaccines against important tumor targets, including EGFR (35) and HER-2 (36). HER-2 specific mimotopes were generated via biopanning of phage display libraries with trastuzumab, and the deduced peptides were coupled to immunogenic carriers, such as keyhole limpet hemocyanin, for vaccination (37), or they were expressed as fusion proteins with carriers, such as adeno-associated viruses (AAV) or AAV-like particles (AAVLPs), with predictably high safety (38). The antigenicity, immunogenicity and tumoricidic effects of the HER-2 mimotope vaccines were demonstrated in vitro and in vivo in previous studies (37). The vaccine-induced HER-2 reactive trastuzumab-like antibodies also showed significant tumor inhibitory effects on HER-2-overexpressing human SK-BR-3 cell lines due to growth signal inhibition and growth receptor downregulation by internalization. More recently, an AAV-HER-2 vaccine resulted in significantly slower tumor growth in a BALB/c mouse model engrafted with D2F2E2 tumor cells, which expressed the HER-2 transgene (39). Notably, none of the mice showed any signs of vaccine-related side effects, including local or systemic reactions, or the well-described trastuzumab-associated cardiotoxicity (40).

\section{Canine mammary carcinomas resemble human disease}

Neoplasms of the mammary gland complex are the most common tumors in dogs, particularly occurring in non-spayed female individuals with a median age of first occurrence of around nine years $(41,42)$. The incidence in female dogs of any breed is estimated at $50 \%$, of which 40 to $50 \%$ are diagnosed as malignant (43). All of these malignant tumors have the potential to metastasize, either lymphogenously to the regional lymph nodes and the lung, or haematogenously directly to the lung and other distant organs (44). Metastasizing tumors and a tumor size of $>3 \mathrm{~cm}$ result in a poor prognosis in terms of survival (44). Other prognostic factors are histological grade, differentiation of the tumor, and the presence of estrogen and/or progesterone receptors $(45,46)$. Corresponding with human breast cancer, steroid-hormone receptor expression is frequent in canine mammary gland tumors and these receptors are important players in tumor development (44,47-49). In addition, other factors, including p53 overexpression and mutations, HER-2 overexpression or the immunological microenvironment of the tumor, are markedly comparable and show similar clinical correlations in dogs as in the human disease (17-21,44,50-53). Based on the discussed pathophysiological similarities between canine and human mammary gland carcinoma, dog cancer patients could serve as potential model patients for the study of disease biology, and particularly for the development of novel immunotherapies.

Usual treatment options at present are primarily surgery, radiation or chemotherapy $(42,45)$. However, these are far from optimal and are often associated with serious side effects (54-56). The therapy of canine mammary carcinomas is therefore limited and the recurrence of the disease is frequent $(44,57,58)$.

In summary, no optimal therapy for this indication exists to date, and treatment options that are commonly used in human clinical oncology, such as passive immunotherapy, have not yet been implemented in standard veterinary care.

Due to the high molecular homology, we anticipate that a vaccine targeted against HER-2, such as the aforementioned AAV HER-2 mimotope vaccine developed for human patients, could induce functional anti-HER-2 antibodies in dogs that are cross-reactive with the canine DER-2 and result in tumoricidic 


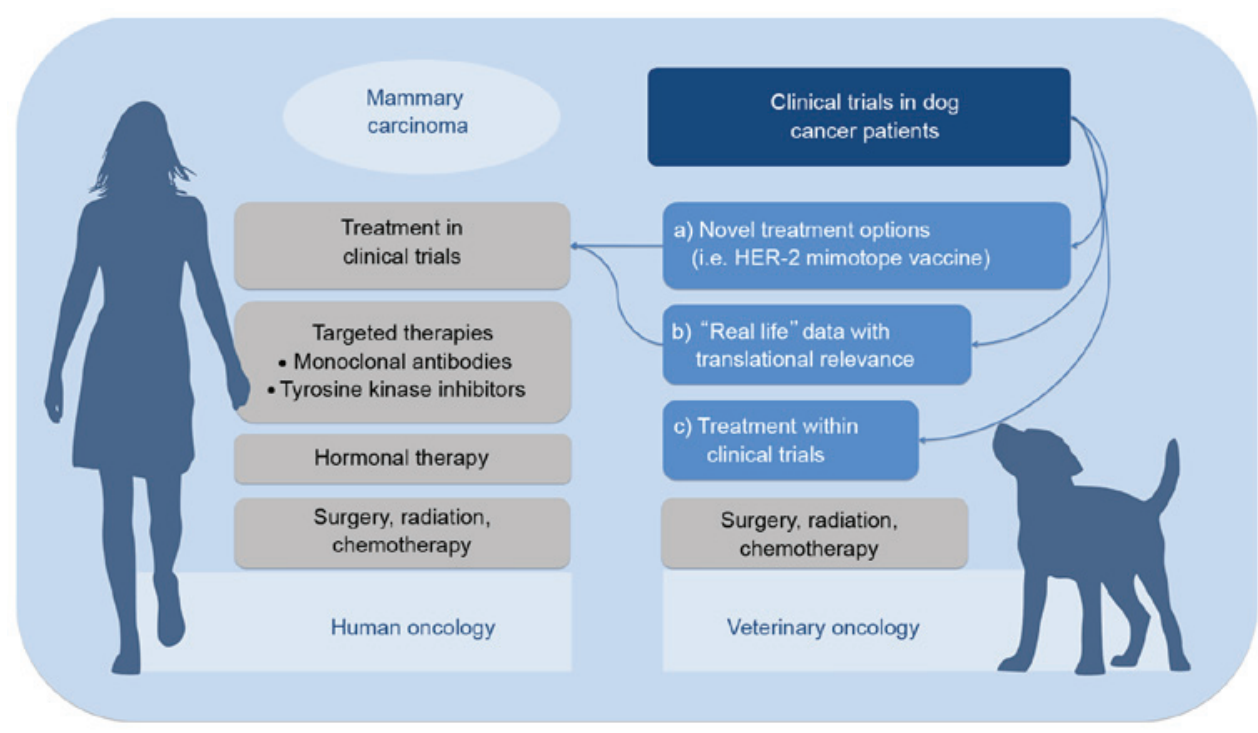

Figure 1. How clinical trials in canine cancer patients could contribute to the development of novel precision medicine options in mammary carcinomas in human and veterinary oncology. Current treatment options in HER-2-positive mammary carcinoma in veterinary and human oncology are represented in grey. Clinical trials in dog cancer patients can contribute by providing 'real life' data that are translatable to human medicine, by introducing novel treatment options in veterinary practice that impact human drug developments, and by granting the opportunity to veterinary patients to participate in clinical trials.

effects. Hence, such an active immunotherapy could be a novel and alternative approach, by inducing a polyclonal immune response with high antibody specificity and by additionally inducing immunological memory (33). In dog model patients, combinatory treatment strategies could be favorably tested. It is likely that a vaccine study in canine cancer patients with spontaneous HER-2-positive mammary gland carcinomas will deliver more robust results for human patients than animal experiments with induced or grafted tumors.

\section{Translational relevance}

It is clear that dogs with naturally occurring cancer would not only gain individual benefit by participating in a clinical trial, but could also act as animal model patients for human disease $(16,46)$. Currently, the development of novel anticancer drugs is quite an inefficient procedure, where only $10.4 \%$ of novel agents that enter clinical phase I trials receive market approval by the Food and Drug Administration (59). The situation is even worse for novel cancer drugs, where this rate drops to only $6.7 \%$, mostly due to the low success rate of anticancer biologicals (59). Another obstacle is that the development of a compound can take up to 15 years (60). The usual procedure of drug-development starts with designing a novel compound on the computer (computer aided drug design) (61) and testing it in vitro. Even though there is a legal requirement to replace animal experiments with alternative, 'animal-free' methods where possible (62), each drug has to be tested for toxicity in at least two animal species (61). Such animal models are also used to gain important information on pharmacokinetics and efficacy prior to being used in clinical trials in humans (63). If a drug has passed all preclinical tests, the clinical development starts with phase 0/I studies in healthy volunteers (or patients in oncological phase I trials), followed by further clinical phase II-IV trials in human patients $(64,65)$.
However, animal patients with similar spontaneous diseases to humans are usually left out during this process of drug development, even though they could serve as 'real life' models for human diseases and are a missing link between the laboratory setting of animal experimentation and the 'real life' conditions (66). Companion animals, and particularly dogs, not only present with a similar pathophysiology of diseases, but also share their human owners' environmental surrounding and lifestyle, and thus are prone to develop similar diseases to humans, including cancer (67-69).

Drug efficacy and safety should be addressed in naturally occurring cancer, as these questions would be difficult to answer in rodent models or in human clinical trials alone. Research in animal patients could thus serve not only to complete data generation in human medicine, but also to establish novel drugs for usage in veterinary medicine itself (70). As described by Paoloni and Khanna (16), the parallel development of the compound SU11654 in dogs and sunitinib (Sutent ${ }^{\circledR}$; Pfizer Inc.) in human cancer patients could act as an example of how the two disciplines could co-operate in respect to the translational development of agents in human and veterinary oncology.

An additional advantage of using the dog cancer patient as an animal model for human disease is the relatively shorter lifespan and thus a shorter time of disease development and response to treatment. This remains true even though the timespan to the conclusion of veterinary clinical trials is longer than experiments in rodent models $(16,70)$. This time aspect would be further supported by the fact that clinical trials in pet patients are not constrained by the usual phase I-III trial designs in human medicine, and novel drugs can be offered to animal patients prior to any other conventional treatment being provided (16). Results that would take years to obtain in human clinical trials could be revealed in a relatively short timespan with dog patients, and then translated to humans. However, testing novel treatment strategies, and specifically 
targeted therapies, in veterinary oncology within clinical trials is not as common as in human oncology. Funding opportunities are rare and the difference to animal experimentation is legally rarely acknowledged (71).

Overall, the clinical development of a drug in human medicine is cost- and time-intensive. With regard to HER-2-positive breast cancer, the high homology of DER-2-positive mammary carcinoma and its responsiveness to specific targeting (21) suggest that canine cancer patients could act as a 'real-life model' for human cancer patients. Furthermore, translating well-established therapeutic strategies from human to veterinary oncology would improve the currently available therapeutic options (Fig. 1).

\section{Conclusion: Where we stand}

The differences in the therapies available to humans compared to those available to animals are very evident, particularly in oncology. Present cancer treatments for pet animals are frequently one step behind human medicine. Thus, surgery, chemotherapy and, if available, radiation therapy represent the most commonly applied treatment options for companion animals. In the meantime, targeted therapies have become indispensable treatment options in human oncology, either as registered therapeutics or as drugs under clinical development. A particularly important change has occurred with regard to implications for the HER-2-positive breast cancer diagnosis in women. HER-2-positivity used to be regarded as an indicator of a bad prognosis (3), however, this evaluation has changed completely in the last 17 years due to the availability of personalized anti-HER-2 therapies that have significantly improved treatment outcomes $(1,8,12)$.

Comparative medicine is systematically revealing more and more similarities in the pathophysiology of a number of diseases, particularly in the comparison between humans and pet animals, such as the example of HER-2-positive mammary tumors in dogs (17-21). This knowledge can be used to gain benefits in each field by simultaneous and thus faster development of novel drugs $(72,73)$.

Since cancer incidence rates are also increasing in veterinary medicine (74), the development of targeted therapies is greatly required. However, simply translating human monoclonal antibodies into veterinary medicine is not an option; they have to be specifically adapted for each species in order to prevent immunogenicity and adverse reactions. Only two antibodies have thus far been 'caninized' for use in dog cancer patients $(26,27)$. Therefore, the idea of developing an AAVLP HER-2 mimotope vaccine that induces trastuzumab-like immunoglobulins would be a cost-effective and species-independent alternative, and also of great interest to human oncology. The clinical development of such a novel treatment option for animal patients would gain robust clinical 'real life' data with a higher predictive value for translation into human medicine as well.

In conclusion, clinical trials in comparative oncology settings may be of increasing importance in the future, but not only for animals. The trials could provide translational evidence for applications in humans, and allow the fast and efficient verification of novel combinatorial treatments. Anticancer vaccines, such as the AAVLP-HER-2 mimotope approach could be particularly effective; they can be applied independent of species as long as the homology of the target antigen is high, such as in the case of HER-2 and DER-2.

\section{Acknowledgements}

The present study was supported by the Austrian Science Fund projects P 23398-B11, by W1205-B09 (doctoral program Cell Communication in Health and Disease), and by Biomedical International R+D GmbH (Vienna, Austria). The authors would like to thank Ms. Amelia Wein (Interuniversity Messerli Research Institute, Vienna, Austria) for proofreading the original manuscript.

\section{References}

1. Slamon DJ, Leyland-Jones B, Shak S, Fuchs H, Paton V, Bajamonde A, Fleming T, Eiermann W, Wolter J, Pegram M, et al: Use of chemotherapy plus a monoclonal antibody against HER2 for metastatic breast cancer that overexpresses HER2. N Eng1 J Med 344: 783-792, 2001.

2. Slamon DJ, Godolphin W, Jones LA, Holt JA, Wong SG, Keith DE, Levin WJ, Stuart SG, Udove J, Ullrich A, et al: Studies of the HER-2/neu proto-oncogene in human breast and ovarian cancer. Science 244: 707-712, 1989.

3. Slamon DJ, Clark GM, Wong SG, Levin WJ, Ullrich A and McGuire WL: Human breast cancer: Correlation of relapse and survival with amplification of the HER-2/neu oncogene. Science 235: 177-182, 1987.

4. Tan M, Yao J and Yu D: Overexpression of the c-erbB-2 gene enhanced intrinsic metastasis potential in human breast cancer cells without increasing their transformation abilities. Cancer Res 57: 1199-1205, 1997.

5. Yu D and Hung MC: Overexpression of ErbB2 in cancer and ErbB2-targeting strategies. Oncogene 19: 6115-6121, 2000.

6. Knuefermann C, Lu Y, Liu B, Jin W, Liang K, Wu L, Schmidt M, Mills GB, Mendelsohn J and Fan Z: HER2//PI-3K//Akt activation leads to a multidrug resistance in human breast adenocarcinoma cells. Oncogene 22: 3205-3212, 2003.

7. Hudis CA: Trastuzumab-mechanism of action and use in clinical practice. N Engl J Med 357: 39-51, 2007.

8. Perez EA, Romond EH, Suman VJ, Jeong JH, Davidson NE, Geyer CE Jr, Martino S, Mamounas EP, Kaufman PA and Wolmark N: Four-year follow-up of trastuzumab plus adjuvant chemotherapy for operable human epidermal growth factor receptor 2-positive breast cancer: Joint analysis of data from NCCTG N9831 and NSABP B-31. J Clin Oncol 29: 3366-3373, 2011.

9. Singh JC, Jhaveri K and Esteva FJ: HER2-positive advanced breast cancer: Optimizing patient outcomes and opportunities for drug development. Br J Cancer 111: 1888-1898, 2014.

10. Rimawi MF, Schiff R and Osborne CK: Targeting HER2 for the treatment of breast cancer. Annu Rev Med 66: 111-128, 2015.

11. Swain SM, Baselga J, Kim SB, Ro J, Semiglazov V, Campone M, Ciruelos E, Ferrero JM, Schneeweiss A, Heeson S, et al: Pertuzumab, trastuzumab, and docetaxel in HER2-positive metastatic breast cancer. N Engl J Med 372: 724-734, 2015.

12. Mukohara T: Role of HER2-targeted agents in adjuvant treatment for breast cancer. Chemother Res Pract 2011: 730360, 2011.

13. de Azambuja E, Holmes AP, Piccart-Gebhart M, Holmes E, Di Cosimo S, Swaby RF, Untch M, Jackisch C, Lang I, Smith I, et al: Lapatinib with trastuzumab for HER2-positive early breast cancer (NeoALTTO): Survival outcomes of a randomised, open-label, multicentre, phase 3 trial and their association with pathological complete response. Lancet Oncol 15: 1137-1146, 2014.

14. Hahn KA, Ogilvie G, Rusk T, Devauchelle P, Leblanc A, Legendre A, Powers B, Leventhal PS, Kinet JP, Palmerini F, et al: Masitinib is safe and effective for the treatment of canine mast cell tumors. J Vet Intern Med 22: 1301-1309, 2008.

15. London CA, Malpas PB, Wood-Follis SL, Boucher JF, Rusk AW, Rosenberg MP, Henry CJ, Mitchener KL, Klein MK, Hintermeister JG, et al: Multi-center, placebo-controlled, double-blind, randomized study of oral toceranib phosphate (SU11654), a receptor tyrosine kinase inhibitor, for the treatment of dogs with recurrent (either local or distant) mast cell tumor following surgical excision. Clin Cancer Res 15: 3856-3865, 2009 
16. Paoloni $\mathrm{M}$ and Khanna C: Translation of new cancer treatments from pet dogs to humans. Nat Rev Cancer 8: 147-156, 2008.

17. Gamba CO, Dias EJ, Ribeiro LG, Campos LC, Estrela-Lima A, Ferreira E and Cassali GD: Histopathological and immunohistochemical assessment of invasive micropapillary mammary carcinoma in dogs: A retrospective study. Vet J 196: 241-246, 2013.

18. Ressel L, Puleio R, Loria GR, Vannozzi I, Millanta F, Caracappa S and Poli A: HER-2 expression in canine morphologically normal, hyperplastic and neoplastic mammary tissues and its correlation with the clinical outcome. Res Vet Sci 94 299-305, 2013

19. Muhammadnejad A, Keyhani E, Mortazavi P, Behjati F and Haghdoost IS: Overexpression of her-2/neu in malignant mammary tumors; translation of clinicopathological features from dog to human. Asian Pac J Cancer Prev 13: 6415-6421, 2012.

20. Kim JH, Im KS, Kim NH, Yhee JY, Nho WG and Sur JH: Expression of HER-2 and nuclear localization of HER-3 protein in canine mammary tumors: Histopathological and immunohistochemical study. Vet J 189: 318-322, 2011.

21. Singer J, Weichselbaumer M, Stockner T, Mechtcheriakova D, Sobanov Y, Bajna E, Wrba F, Horvat R, Thalhammer JG, Willmann $M$ and Jensen-Jarolim E: Comparative oncology: ErbB-1 and ErbB-2 homologues in canine cancer are susceptible to cetuximab and trastuzumab targeting. Mol Immunol 50: 200-209, 2012

22. Peña L, Gama A, Goldschmidt MH, Abadie J, Benazzi C, Castagnaro M, Díez L, Gärtner F, Hellmén E, Kiupel M, et al Canine mammary tumors: A review and consensus of standard guidelines on epithelial and myoepithelial phenotype markers, HER2, and hormone receptor assessment using immunohistochemistry. Vet Pathol 51: 127-145, 2014.

23. Pichler WJ: Adverse side-effects to biological agents. Allergy 61 : 912-920, 2006

24. Corominas M, Gastaminza G and Lobera T: Hypersensitivity reactions to biological drugs. J Investig Allergol Clin Immunol 24: 212-225, 2014.

25. Baldo BA: Adverse events to monoclonal antibodies used for cancer therapy: Focus on hypersensitivity responses. Oncoimmunology 2: e26333, 2013.

26. Singer J, Fazekas J, Wang W, Weichselbaumer M, Matz M, Mader A, Steinfellner W, Meitz S, Mechtcheriakova D, Sobanov Y, et al: Generation of a canine anti-EGFR (ErbB-1) antibody for passive immunotherapy in dog cancer patients. Mol Cancer Ther 13: 1777-1790, 2014.

27. Rue SM, Eckelman BP, Efe JA, Bloink K, Deveraux QL, Lowery D and Nasoff $M$ : Identification of a candidate therapeutic antibody for treatment of canine B-cell lymphoma. Vet Immunol Immunopathol 164: 148-159, 2015.

28. Jensen-Jarolim E and Singer J: Cancer vaccines inducing antibody production: More pros than cons. Expert Rev Vaccines 10 1281-1289, 2011

29. Milani A, Sangiolo D, Montemurro F, Aglietta M and Valabrega G: Active immunotherapy in HER2 overexpressing breast cancer: Current status and future perspectives. Ann Oncol 24: 1740-1748, 2013.

30. Anderson KS: Tumor vaccines for breast cancer. Cancer Invest 27: 361-368, 2009.

31. Sears AK, Perez SA, Clifton GT, Benavides LC, Gates JD, Clive KS, Holmes JP, Shumway NM, Van Echo DC, Carmichael MG, et al: AE37: A novel T-cell-eliciting vaccine for breast cancer. Expert Opin Biol Ther 11: 1543-1550, 2011

32. NCT01730118, Ad/HER2/Neu dendritic cell cancer vaccine testing. https://clinicaltrials.gov/. Accessed August 31, 2015.

33. Knittelfelder R, Riemer AB and Jensen-Jarolim E: Mimotope vaccination-from allergy to cancer. Expert Opin Biol Ther 9: 493-506, 2009

34. Ashok BT, David L, Chen YG, Garikapaty VP, Chander B, Kanduc D, Mittelman A and Tiwari RK: Peptide mimotopes of oncoproteins as therapeutic agents in breast cancer. Int J Mol Med 11: 465-471, 2003.

35. Riemer AB, Kurz H, Klinger M, Scheiner O, Zielinski CC and Jensen-Jarolim E: Vaccination with cetuximab mimotopes and biological properties of induced anti-epidermal growth factor receptor antibodies. J Natl Cancer Inst 97: 1663-1670, 2005.

36. Riemer AB, Kraml G, Scheiner O, Zielinski CC and Jensen-Jarolim E: Matching of trastuzumab (Herceptin) epitope mimics onto the surface of Her-2/neu-a new method of epitope definition. Mol Immunol 42: 1121-1124, 2005.
37. Riemer AB, Klinger M, Wagner S, Bernhaus A, Mazzucchelli L, Pehamberger H, Scheiner O, Zielinski CC and Jensen-Jarolim E: Generation of Peptide mimics of the epitope recognized by trastuzumab on the oncogenic protein Her-2/neu. J Immunol 173 : 394-401, 2004

38. Manzano-Szalai K, Thell K, Willensdorfer A, Weghofer M, Pfanzagl B, Singer J, Ritter M, Stremnitzer C, Flaschberger I, Michaelis U and Jensen-Jarolim E: Adeno-associated virus-like particles as new carriers for B-cell vaccines: Testing immunogenicity and safety in BALB/c mice. Viral Immunol 27: 438-448, 2014.

39. SingerJ,Manzano-SzalaiK,FazekasJ,ThellK,Bentley-Lukschal A, Stremnitzer C, Roth-Walter F, Weghofer M, Ritter M, Tossi $\mathrm{KP}$, et al: Proof of concept study with a HER-2 mimotope anti-cancer vaccine deduced from a novel AAV-mimotope library platform. Oncoimmunology: e1171446, 2016.

40. Valicsek E, Kószó R, Dobi Á, Uhercsák G, Varga Z, Vass A, Jebelovszky É and Kahán Z: Cardiac surveillance findings during adjuvant and palliative trastuzumab therapy in patients with breast cancer. Anticancer Res 35: 4967-4973, 2015.

41. Dobson JM, Samuel S, Milstein H, Rogers K and Wood JL: Canine neoplasia in the UK: Estimates of incidence rates from a population of insured dogs. J Small Anim Pract 43: 240-246, 2002.

42. Arnold-Gloor S, Hubler M and Reichler I: Diseases of the mammary gland. In: Placement of teh dog clinic. Suter PF, Arnold-Gloor S and Niemand HG (eds.) Parey, Stuttgart, pp881-883, 2006 (In German).

43. Baba AI, Câtoi C and Baba AI: Mammary gland tumours-comparative oncology. The publishing house of the Romanian academy, Bucharest, p 1 online resource, 2007. www. ncbi.nlm.nih.gov/books/NBK9557/. Accessed August 31, 2015

44. Sorenmo K: Canine mammary gland tumors. Vet Clin North Am Small Anim Pract 33: 573-596, 2003.

45. Novosad CA: Principles of treatment for mammary gland tumors. Clin Tech Small Anim Pract 18: 107-109, 2003.

46. Queiroga FL, Raposo T, Carvalho MI, Prada J and Pires I: Canine mammary tumours as a model to study human breast cancer: Most recent findings. In vivo 25: 455-465, 2011.

47. de Las Mulas JM, Millán Y and Dios R: A prospective analysis of immunohistochemically determined estrogen receptor alpha and progesterone receptor expression and host and tumor factors as predictors of disease-free period in mammary tumors of the dog. Vet Pathol 42: 200-212, 2005.

48. Queiroga FL, Pérez-Alenza MD, Silvan G, Peña L, Lopes C and Illera JC: Role of steroid hormones and prolactin in canine mammary cancer. J Steroid Biochem Mol Biol 94: 181-187, 2005.

49. Torres CG, Pino AM and Sierralta WD: A cyclized peptide derived from alpha fetoprotein inhibits the proliferation of ER-positive canine mammary cancer cells. Oncol Rep 21: 1397-1404, 2009

50. Wakui S, Muto T, Yokoo K, Yokoo R, Takahashi H, Masaoka T, Hano $\mathrm{H}$ and Furusato M: Prognostic status of p53 gene mutation in canine mammary carcinoma. Anticancer Res 21: 611-616, 2001.

51. Lee $\mathrm{CH}$ and Kweon OK: Mutations of p53 tumor suppressor gene in spontaneous canine mammary tumors. J Vet Sci 3: 321-325, 2002.

52. Carvalho MI, Pires I, Prada J and Queiroga FL: A role for T-lymphocytes in human breast cancer and in canine mammary tumors. Biomed Res Int 2014: 130894, 2014.

53. Haga S, Nakayama M, Tatsumi K, Maeda M, Imai S, Umesako S, Yamamoto H, Hilgers J and Sarkar NH: Overexpression of the p53 gene product in canine mammary tumors. Oncol Rep 8: $1215-1219,2001$

54. Tao JJ, Visvanathan K and Wolff AC: Long term side effects of adjuvant chemotherapy in patients with early breast cancer. Breast 24 (Suppl 2): S149-S153, 2015.

55. Bracha S, Walshaw R, Danton T, Holland S, Ruaux C and Obradovich J: Evaluation of toxicities from combined metronomic and maximal-tolerated dose chemotherapy in dogs with osteosarcoma. J Small Anim Pract 55: 369-374, 2014.

56. Selmic LE, Burton JH, Thamm DH, Withrow SJ and Lana SE: Comparison of carboplatin and doxorubicin-based chemotherapy protocols in 470 dogs after amputation for treatment of appendicular osteosarcoma. J Vet Intern Med 28: 554-563, 2014.

57. Stratmann N, Failing K, Richter A and Wehrend A: Mammary tumor recurrence in bitches after regional mastectomy. Vet Surg 37: 82-86, 2008. 
58. Betz D, Schoenrock D, Mischke R, Baumgärtner W and Nolte I: Postoperative treatment outcome in canine mammary tumors. Multivariate analysis of the prognostic value of pre- and postoperatively available information. Tierarztl Prax Ausg K Kleintiere Heimtiere 40: 235-242, 2012 (In English, German).

59. Hay M, Thomas DW, Craighead JL, Economides C and Rosenthal J: Clinical development success rates for investigational drugs. Nat Biotechnol 32: 40-51, 2014

60. Marchetti S and Schellens JH: The impact of FDA and EMEA guidelines on drug development in relation to Phase 0 trials. Br J Cancer 97: 577-581, 2007.

61. Stapff M: Drug trials: An introduction to clinical trials for doctors, students, medical assistants and interested laymen. 5th edition. Zuckschwerdt, Munich, 2008.

62. Directive 2010/63/EU: Directive 2010/63/EU of the European Parliament and of the Council of 22 September 2010 on the protection of animals used for scientific purposes. 2010. eur-lex. europa.eu/LexUriServ/LexUriServ.do?uri=OJ:L:2010:276:0033: 0079:en:PDF. Accessed May 17, 2016.

63. European Medicines Agency: ICH-GCP: ICH Topic E6 (R1) Guideline for Good Clinical Practice. 2002. eur-lex.europa.eu/ legalcontent/EN/TXT/?uri=celex\%3A32010L0063. Accessed August 31, 2015.

64. National Institutes of Health: U.S. National Library of Medicine: Clinical Trial Phases. 2015. clinicaltrials.gov. Accessed August 31, 2015.

65. Ciociola AA, Cohen LB and Kulkarni P; FDA-Related Matters Committee of the American College of Gastroenterology: How drugs are developed and approved by the FDA: Current process and future directions. Am J Gastroenterol 109: 620-623, 2014.
66. Khanna C, London C, Vail D, Mazcko C and Hirschfeld S: Guiding the optimal translation of new cancer treatments from canine to human cancer patients. Clin Cancer Res 15: 5671-5677, 2009.

67. Monath TP, Kahn LH and Kaplan B: Introduction: One health perspective. ILAR J 51: 193-198, 2010.

68. Séveré S, Marchand P, Guiffard I, Morio F, Venisseau A, Veyrand B, Le Bizec B, Antignac JP and Abadie J: Pollutants in pet dogs: A model for environmental links to breast cancer. Springerplus 4: 27, 2015.

69. Kelsey JL, Moore AS and Glickman LT: Epidemiologic studies of risk factors for cancer in pet dogs. Epidemiol Rev 20: 204-217, 1998.

70. Hansen K and Khanna C: Spontaneous and genetically engineered animal models; use in preclinical cancer drug development. Eur J Cancer 40: 858-880, 2004.

71. Fürdös I, Fazekas J, Singer J and Jensen-Jarolim E: Translating clinical trials from human to veterinary oncology and back. J Transl Med 13: 265, 2015.

72. Jensen-Jarolim E (ed): Definition of comparative medicine: History and new identity. In: Comparative Medicine. Anatomy and Physiology. Springer, Wien, pp1-18, 2014.

73. Singer J and Jensen-Jarolim E: IgE-based immunotherapy of cancer-a comparative oncology approach. J Carcinog Mutagen 5: 1000176, 2014.

74. Merlo DF, Rossi L, Pellegrino C, Ceppi M, Cardellino U, Capurro C, Ratto A, Sambucco PL, Sestito V, Tanara G and Bocchini V: Cancer incidence in pet dogs: Findings of the Animal Tumor Registry of Genoa, Italy. J Vet Intern Med 22: 976-984, 2008 